\title{
RESILIENCE-BUILDING WITH DISABLED CHILDREN AND YOUNG PEOPLE: A REVIEW AND CRITIQUE OF THE ACADEMIC EVIDENCE BASE
}

\author{
Angie Hart, Becky Heaver, Elinor Brunnberg, Anette Sandberg, Hannah Macpherson, \\ Stephanie Coombe, and Elias Kourkoutas
}

\begin{abstract}
The aim of this paper was to review published accounts of resilience-based approaches with and for disabled children and young people aged up to 25 years. The review is part of a broader study looking more generally at resilience-based interventions with and for young people. The authors attempt to summarise the approaches and techniques that might best support those children and young people who need them the most. However, when compared to the number of evaluated resilience-based approaches to working with typically-developing children and young people, those including children and young people with complex needs are disappointingly lacking. Of 830 retrieved references, 46 were relevant and 23 met the inclusion criteria and form the body of this review. They covered a variety of intervention content, setting, and delivery, and diverse children and young people, making comparative evaluation prohibitive. The difficulties in identifying suitable resilience-based interventions are discussed, together with the authors' iterative approach, which was informed by realist review methodology for complex social interventions. The review is set into a context of exclusion, an ableist mindset and the political economy of research. It also provides recommendations for future research and practice development in this field.
\end{abstract}

Keywords: resilience, intervention, disability, young people, review

Acknowledgement: The authors would like to thank Marina Trowell for her assistance with article screening and translation.

Correspondence concerning this article should be addressed to Professor Angie Hart, Centre for Health Research, University of Brighton, 264 Mayfield House, Falmer, Brighton, BN1 9PH, United Kingdom. Tel: +44(0)1273 644051 Fax: +44(0)1273 644541

E-mail: a.hart@brighton.ac.uk 
International Journal of Child, Youth and Family Studies (2014) 5(3): 394-422

Angie Hart is Professor of Child, Family \& Community Health at Centre for Health Research, Mayfield House, University of Brighton, Falmer, Brighton, BN1 9PH, UK. E-mail: a.hart@brighton.ac.uk

Becky Heaver is Research Officer at Centre for Health Research, Mayfield House, University of Brighton, Falmer, Brighton, BN1 9PH, UK. E-mail: b.heaver@brighton.ac.uk

Elinor Brunnberg is Professor of Social Work at School of Health, Care and Social Welfare, Mälardalen University, Drottninggatan 16A, Eskilstuna, Sweden.

E-mail: elinor.brunnberg@mdh.se

Anette Sandberg is Professor of Education at School of Education, Culture and Communication, Mälardalen University, Högskoleplan 1, Västerås, Sweden.

E-mail: anette.sandberg@mdh.se

Hannah Macpherson is Senior Lecturer in Human Geography at School of Environment and Technology, Cockcroft Building, University of Brighton, Lewes Road, Moulsecoomb, Brighton, BN2 4GJ, UK. E-mail: hm139@brighton.ac.uk

Stephanie Coombe is Ph.D. Student at Centre for Health Research, Mayfield House, University of Brighton, Falmer, Brighton, BN1 9PH, UK. E-mail: $\underline{\text { S.I.Green@brighton.ac.uk }}$

Elias Kourkoutas is Associate Professor of Psychopathology and Special Education at Department of Primary Education, University of Crete, Gallos Campus, Rethymnon, Crete, GR-74100, Greece. E-mail: hkourk@edc.uoc.gr 
Resilience may be usefully viewed as positive development despite adversity (see Hart, Blincow, \& Thomas, 2007; Masten, 2011; Rutter, 2006; Ungar, 2012). Hart et al. (2007) suggest that "resilience is evident where people with persistently few assets and resources, and major vulnerabilities ... have better outcomes than we might expect given their circumstances, and in comparison to ... other children in their contexts” (p. 10).

There is a vast academic literature on resilience-building with children and young people, and the benefits and outcomes of interventions or programs designed to enhance specific or general aspects of their resilience. These include concrete progress, such as improved confidence, coping and self-esteem, and less measureable outcomes, such as doing better than expected, or simply maintaining the status quo (Hart et al., 2007). These benefits are of particular importance to children and young people with disabilities, who face additional adversity, disadvantage, and challenges to their development. The purpose of the review is to summarise which resilience interventions were effective in enhancing resilience, and with what populations, with a focus on whether and how children and young people with disabilities were included in academic studies of explicit resilience-building approaches. Prior to interrogating the evidence base, this article sets out why it focuses on children and young people with disabilities and the enhancement of resilience, how we define disability, and the approach used to conduct the review.

There is a strong link between disability, exclusion, and socioeconomic inequality (Hosseinpoor et al., 2013), and the implications for children and young people with disabilities depend on the nature of their disability, where they live, their culture, socioeconomic status, and gender (United Nations Children's Emergency Fund [UNICEF], 2013b; van Campen \& van Santvoort, 2013). Figures show that in particular, education, training, and employment opportunities for girls with disabilities are fewer than for girls without disabilities, and even boys with disabilities (Groce, 2004). Children with long-term illnesses or disabilities have been shown to underperform in educational attainment, maths, verbal and non-verbal skills, at age seven, compared to their non-disabled peers (Jones, Gutman, \& Platt, 2013). Contact a Family (2013) recently reported that children with disabilities experience illegal exclusions from school on a regular basis in England and Wales.

Young people with neurodevelopmental conditions, learning or mental health difficulties, in the United Kingdom, United States, and Canada, are more likely to go to prison than other young people because the youth justice system is failing to recognise their needs (Doob \& Cesaroni, 2004; Hughes, Williams, Chitsabesan, Davies, \& Mounce, 2012; Odgers, Burnette, Chauhan, Moretti, \& Reppucci, 2005; Talbot, 2010). Swedish adolescents with disabilities are more likely to experience psychological symptoms (Brunnberg, Lindén Boström, \& Berglund, 2007) and abuse, such as force at sexual debut, than adolescents without disabilities (Brunnberg, Lindén Boström, \& Berglund, 2012). A study from Switzerland compared the prevalence and intensity of victimisation from bullying and found higher rates of teasing, physical aggression, and social exclusion for adolescents with chronic conditions compared to young people without chronic conditions (Pittet, Berchtols, Akre, Michaud, \& Suris, 2010). Young people with a learning difficulty may also be at increased risk of substance misuse, which Cosden (2001) suggests may be a negative coping strategy related to the developmental need for family support over a longer period of time, increased difficulty in making friendships with peers, and a lack of understanding of the effects of their own disability. The general pressures of living in an ableist society are also likely to contribute. 
The World Health Association (WHO) considers participation in age-appropriate activities to be essential for understanding functioning of children with disabilities (WHO, 2007). It also improves children's social relationships, academic performance, mental health, physical health, and skills and competencies (Forsyth \& Jarvis, 2002; Janssen \& Leblanc, 2010; Mâsse, Miller, Shen, Schiariti, \& Roxborough, 2013). However, it is clear that children and young people with disabilities are often excluded from activities others take for granted, many of which can help to build resilience. For example, Mâsse et al. (2013) found that in Canadian schools, children with a range of disabilities were restricted from participating in educational, physical, and social/recreational activities such as art/music lessons or summer camp, particularly if they were from poorer families or had more severe disabilities.

Perusing the resilience literature, it seems to us that most academic research is conducted from a psychological or medical view of disability (e.g., Lee et al., 2009; Storch et al., 2012), instead of a social model of disability (e.g., Evans \& Plumridge, 2007; RunswickCole \& Goodley, 2013). Some have even critiqued the concept of resilience itself, for making implicitly ableist assumptions and being conflated with normative perspectives on health (Hutcheon \& Wolbring, 2013). This is clearly a contested area, hence an important question to consider is what is meant by disability, and how it will be defined and measured relative to this review, in order to answer the question: whether and how children and young people with disabilities are included in academic studies of explicit resilience-building approaches.

In writing this paper our interest in resilience from a disability perspective, as researchers, parents, and practitioners, arises in part from our personal circumstances. Our group of seven includes adults who identify as having disabilities, parents of children with complex needs, and practitioners who work day-to-day with disabled children and young people. Exploration within our team revealed 25 conditions or differences perceived by society as disabilities, including physical disabilities, neurodiversity, sensory impairment, chronic medical conditions, learning difficulties, and mental health difficulties.

\section{Method}

According to the WHO (2012):

'Disabilities' is an umbrella term, covering impairments, activity limitations, and participation restrictions. An impairment is a problem in body function or structure; an activity limitation is a difficulty encountered by an individual in executing a task or action; while a participation restriction is a problem experienced by an individual in involvement in life situations. Thus disability is a complex phenomenon, reflecting an interaction between features of a person's body and features of the society in which he or she lives.

Whilst this is the definition of disability we are using, we cannot do it justice because it rendered our search unfeasibly large. The issue of defining "disability” is itself subjective, multifarious, and incredibly nuanced. It has implications for those who do or do not fit a particular definition, and corresponds to a vast and growing disability studies literature from a variety of theoretical perspectives (e.g., Salvador-Carulla \& Gasca, 2010; Schalock \& Luckasson, 2013). Understandably, the way that disability is defined can affect the research findings (Grönvik, 2009), but including a wide range of disability-related search terms made the search broad and non-specific. Therefore we took a pragmatic approach. Disability in this review was conceived to include children and young people fitting the WHO (2012) definition of disability, but in particular those with physical disability, severe or chronic physical or psychiatric illness, and learning difficulty, mostly referred to in the research base 
as learning, cognitive, or intellectual disability, despite preference of the term "learning difficulties” by self-advocates who have them (Goodley, 2005).

Limited time and resources made a wider search impractical. Therefore we did not specifically include mental health/illness search terms, which themselves return a vast number of results. This is in part due to the popularity of "well-being" programs and the perceived preventative nature of resilience interventions aimed at preventing depression, anxiety and stress, and increasing socio-emotional competence in typically-developing children and young people with average levels of need. The aim of our review was not to look at broad interventions aimed at the mental health of the general population, but those focused specifically on children and young people with the most long-term and complex needs.

Our review methodology grew out of the "realist" review approach for complex social interventions (Pawson, Greenhalgh, Harvey, \& Walshe, 2005), which aims to identify what works for whom, in what circumstances, in what respects and how. Resilience-enhancing interventions generally do not suit a traditional review approach due to a lack of comparable elements. We formulated some broad aims in consultation with the parents and practitioners with whom we regularly work, and incorporated these into an iterative, flexible approach outlined below (as per Hart \& Heaver, 2013).

A parsimonious search was made using disability search terms (disabl* OR disabilit* OR autis* OR chronic OR EBD OR severe) in conjunction with resilien* AND (youth OR young OR child* OR adolescen*). Additional search terms (e.g., "complex”, or terms relating to specific acquired and congenital conditions and disabilities, sensory impairment, psychiatric illness, neurodiversity or learning difficulties) did not increase the number of (relevant) results; therefore it was concluded that these concise terms were sufficient, and would be included in most papers concerning children and young people with a disability. Children and young people with what is generally termed "severe" mental health or behavioural problems were captured by inclusion of the search terms "severe" or (psychiatric) "disability". The authors assessed whether or not papers included evaluated interventions on the basis of the abstract, rather than through search terms, as many unsuitable articles include the word "intervention" in the abstract referring to future directions.

Articles were initially retrieved from the literature by searching EBSCO databases (AMED, British Nursing Index, CINAHL, Criminal Justice Abstracts, eBook Collection, EJournals, PsycARTICLES, PsycINFO, SPORTDiscus), Expanded Academic ASAP, AEI, BEI, ERIC, IBSS, PubMed, Web of Science (incl. Medline), ScienceDirect, and Swedish databases Artikelsök and SwePuB, for articles between 2000 and 2013, which included resilience keywords in the title, and keywords related to disability and age group in the abstract. The search for articles emanating from the Nordic countries produced no results. Articles originated from countries including U.S.A., Canada, Hong Kong, South Africa, Taiwan, Mexico, Wales, Japan, Germany, and France, and were mostly written in English. Additional publications were identified in an iterative process via Google Scholar, hand searching reference lists, and discussion with colleagues.

The authors screened 398 of the 830 retrieved references, and identified 46 documents as relevant on the basis of their title and abstract. In groups of 2 to 3 we reviewed each full text collaboratively, initially agreeing on $96 \%$ of the articles, and reaching $100 \%$ consensus on all papers after brief discussion. We considered 23 of the 46 articles to have met the inclusion criteria for the review (see Figure 1). 
Figure 1: The review process.

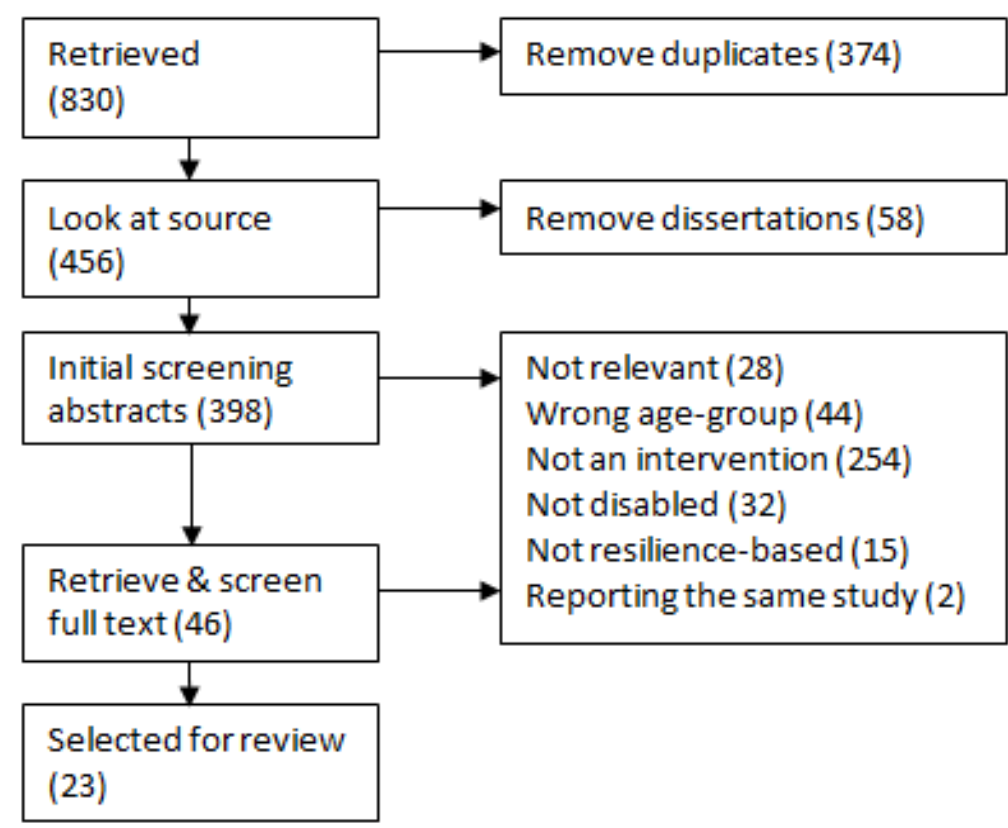

Initial inclusion criteria for the search were: At least some of the participants were children or young people aged 0 to 25 years, or were parents/carers/families/teachers of children or young people; at least some of the participants had a disability as defined previously; the intervention was resilience-based; the intervention was evaluated. Interventions were considered to be resilience-based if the following criteria were met: The authors had engaged with the resilience evidence base and attempted to link their program, or components of their program, with specific resilience-enhancing capacities (see, for example, Mental Health Foundation of Australia, 2005); articles included a definition or explanation of resilience that indicated the authors' orientation with respect to the locus and nature of resilience (e.g., individual asset, dynamic transaction between individual/environment). In an iterative process, we expanded two of the inclusion criteria (that the intervention was resilience-based, and that the intervention was evaluated) in a second search, to increase the number of articles, and therefore the usefulness of the review. Some articles were also included that were not strictly interventions, but were excellent practice examples of resilience-building activities with children and young people with complex needs.

The authors chose the age range because our work focuses on children and young people and the parents and practitioners supporting them. Furthermore, interventions with children and young people is where interventions potentially may make the larger difference. As the age group was so broad, and in line with realist approaches that document the ecological context of the interventions, programs were not required to target predefined developmental or resilience aspects which would be context- and age-specific. However, it was considered essential that discussion of underlying models or theories provided a conceptual basis for why the intervention would be effective in enhancing resilience in that age group (e.g., increased self-esteem).

Consistent with our own practice, experience, and research interests, and because of the connection between inequalities, disability, and adversity, we wanted to capture any information regarding inequalities faced by the children and young people in the studies. Inequality, by and in itself, directly impacts on psychological and physical health, to a degree 
that cannot simply be ameliorated by psychological interventions (Prilleltensky \& Prilleltensky, 2005). An inequalities perspective is imperative when considering children and young people with disabilities and their families, who face additional financial hardship, lack of opportunities, more intense and longer-term caring responsibility, multiple bureaucratic procedures, access barriers, stigma and discrimination, and often have to negotiate with and manage multiple ineffective, unresponsive, and underfunded professionals and services, often reported to work in a disjointed fashion. Resilience scholars, and those writing about resilience interventions, often define "resilience" as residing solely within individuals, rather than as a dynamic interplay between persons and their environments (Hart et al., 2007). Making resilient moves with and/or on behalf of children and young people may be seen as a response to inequalities; therefore, resilience-based interventions might well include an inequalities dimension. The parents and practitioners with whom we are working support children and young people in contexts they would define as complex inequality or disadvantage, those who are "denied access to the tools needed for self-sufficiency" (Mayer, 2003, p. 2). These parents and practitioners were eager to find out more about what best supports these children and young people's resilience.

Detailed information about each intervention was collated to gain an understanding of what worked, for whom and in what context: participant characteristics, method and intensity of delivery, setting and circumstances. To identify whether an intervention satisfied all or most of the inclusion criteria, aspects such as resilience definition, program-theory links, capacities, and measures and outcomes were also recorded. Additional headings collected evaluation design and methodology, program costs, funding and implementation history (where available), and strengths and weaknesses of the program and the evaluation.

\section{Results and Discussion}

When it came to identifying comparable resilience-based, well-evaluated interventions, the reality was bleak. In previous work (Hart \& Heaver, 2013), we had to exclude some useful and innovative articles as they did not meet the inclusion criteria, the most common reasons being that they did not properly relate their study to resilience conceptually, despite using the term in the abstract or keywords. However, when looking for approaches to building resilience with disabled children and young people, had we applied the same strict criteria, just seven of the original 830 papers would have been suitable (Bloemhoff, 2006; Buckner et al., 2005; Leve, Fisher, \& Chamberlain, 2009; Macpherson, Hart, \& Heaver, in press; Mears \& Stevenson, 2006; Theron, 2006; Woodier, 2011).

After the first iteration of our search, we decided to expand our inclusion criteria papers still had to address the population of interest (i.e., children and young people, with some of the sample having a disability), but they were also considered if they were resiliencebased but not evaluated (e.g., Alvord \& Grados, 2005; Burka, 2007; Ellis, Braff, \& Hutchinson, 2001), if their link to the resilience literature was not explicitly stated in the introduction, despite reporting a program that clearly could be conceptualised as increasing resilience (e.g., Ferreyra, 2001; Morison, Bromfield, \& Cameron, 2003; Pelchat, 2010), and in some cases if they were not strictly "interventions", for example describing the benefit of individual resilience-building activities that were not part of an intervention (Jessup, Cornell, \& Bundy, 2010), or existing service provision that was not part of a research project (Evans \& Plumridge, 2007; Morison et al., 2003). With a redefined set of inclusion criteria, the second iteration identified 23 of the papers as suitable for inclusion in this review. 
Originally it was our intention to structure the results section according to the commonly asked questions of our own parent and practitioner collaborators, and attempt to identify what works for whom, in what circumstances, in what respects and how (e.g., Pawson et al., 2005; Hart \& Heaver, 2013). However, there was so little actual data, that this has not been possible. Details that would satisfy these questions, such as cost, are often missing from published evaluations of resilience-based interventions involving participants who do not have disabilities; there is even less information available about interventions for the disabled children and young people who are the focus of this review. Therefore we have taken a slightly different approach, focusing more on what has been done and how, and who has been left out and why, rather than making evaluative comparisons of effectiveness.

\section{Participants}

Approximately 800 children and young people from nine countries participated in the 23 studies, in samples sizes ranging from 2 to 213; Alvord and Grados (2005), Ferreyra (2001), Leve et al. (2009), and Mears and Stevenson (2006) did not provide sample sizes. Despite being key to interpreting the generalisability of their results, a large proportion of the studies omitted to report major demographic characteristics of their samples. Half the studies did not supply information about gender (Alvord \& Grados, 2005; Burka, 2007; Ellis et al., 2001; Evans \& Plumridge, 2007; Ferreyra, 2001; Gauvin-Lepage \& Lefebvre, 2012; Leve et al., 2009; Mears \& Stevenson, 2006; Morison et al., 2003; Pelchat, 2010; Stallard et al., 2005); of the studies that did, around $32 \%$ of participants were female (see Figure 2). The participants were aged 0 to 25 years, with the most commonly included age group being 13 , and those aged between 9 and 18 years were most commonly included (in at least nine studies; see Figure 3).

Figure 2: Gender breakdown of participants.




Figure 3: Frequency of age groups in the studies.

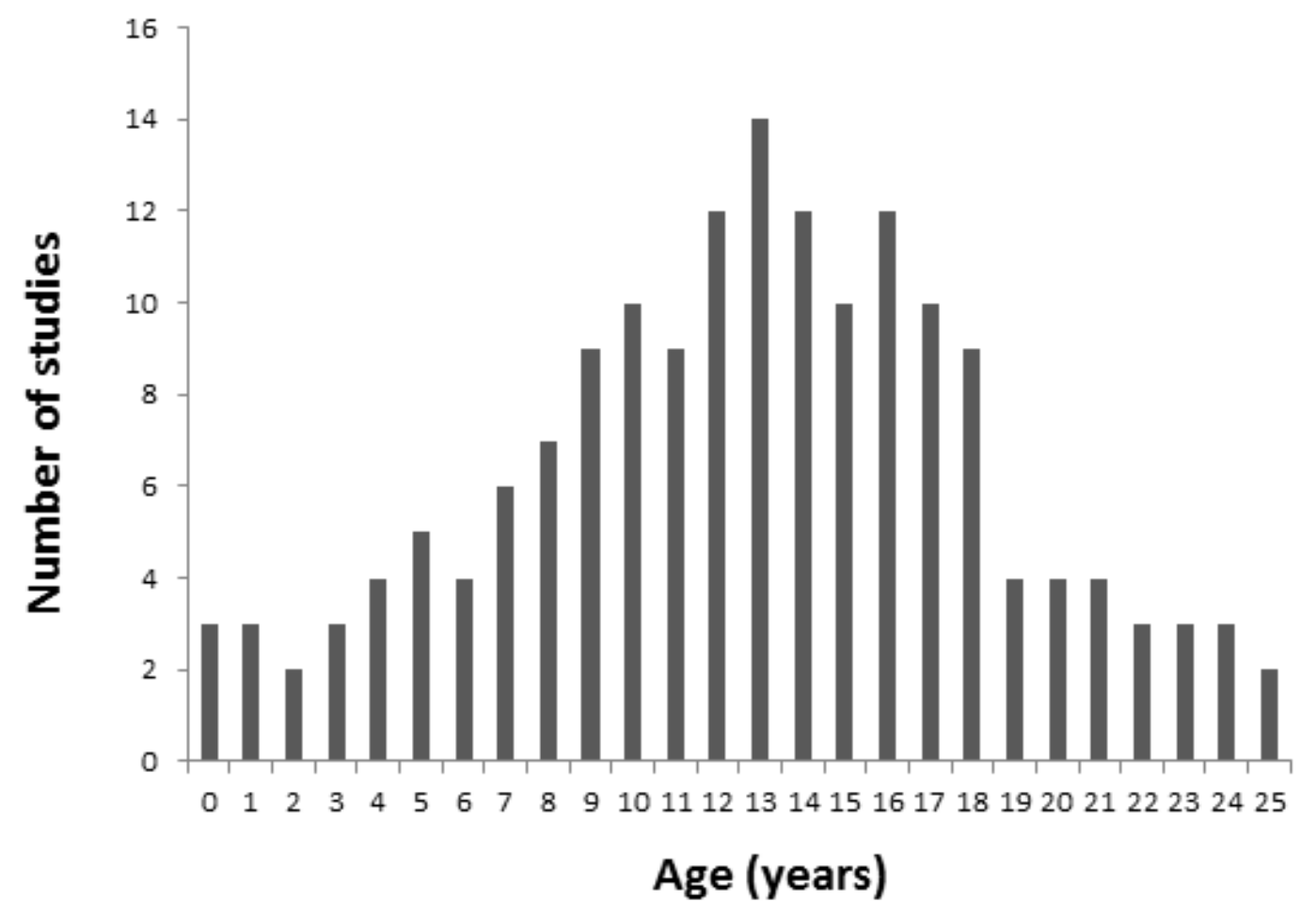

Twenty of the 23 studies included solely disabled children and young people (some with multiple disabilities and complex needs), with the remaining three studies (Ellis et al., 2001; Firth, Frydenberg, Steeg, \& Bond, 2013; Stallard et al., 2005) also including typicallydeveloping peers (see Table 1). Only 6 studies gave any indication of participants' socioeconomic status (Ellis et al., 2001; Ferreyra, 2001; Firth et al., 2013; Irie \& Tsumura, 2011; Lee et al., 2009; Stallard et al., 2005), with five studies reporting race/ethnicity (Buckner et al., 2005; Ferreyra, 2001; Firth et al., 2013; Lee et al., 2009; Storch et al., 2012), and none recording sexual orientation.

\section{What did the studies do exactly, for how long, and with what intensity?}

This review has confirmed our observations from many years of research and practice, that to be effective as practitioners, parents, and researchers in the resilience field, one has to be contextually focused. Perhaps understandably, one of the capacities specific to resiliencebuilding interventions for disabled children and young people that was not mentioned in interventions for typically-developing (or where no specific details of the sample were given, at least assumed to be typically-developing) peers, was "accurate understanding of the illness and its medical and psychosocial consequences" on the individual and the family (Shapiro, 2002, p. 1376). Therefore some interventions included psychoeducation, information, and advice on helping the children and young people/families to cope with their specific condition or disability (e.g., Buckner et al., 2005; Evans \& Plumridge, 2007; Ferreyra, 2001; Firth et al. 2013; Mu \& Chang, 2010; Shapiro, 2002; Storch et al., 2012). However, only two studies 
included identity formation (see Gwernan-Jones, 2008) as a disabled young person (Ferreyra, 2001) or as the family of a disabled child (Mu \& Chang, 2010).

Several interventions had a specific focus for enhancing resilience including: prevention elements such as mental health (Firth et al., 2013; Stallard et al., 2005; Storch et al., 2012) and substance use (Ferreyra, 2001); learning new skills such as problem-solving, social and life skills (Alvord \& Grados, 2005; Ellis et al., 2001; Ferreyra, 2001; Macpherson et al., in press; Mears \& Stevenson, 2006; Theron, 2006); leisure, outdoor activities, and hobbies (Bloemhoff, 2006; Buckner et al., 2005; Burka, 2007; Ellis et al., 2001; Evans \& Plumridge, 2007; Jessup et al., 2010); creative therapies including art/music (Macpherson et al., in press; Theron, 2006); and work experience (Woodier, 2011). Length and intensity was very wide-ranging - from one-off sessions of 1 to 4 hours (Bloemhoff, 2006; Mu \& Chang, 2010) to weekly sessions over 2 to 3 years (Ferreyra, 2001; Woodier, 2011; see Table 1).

Several interventions worked with the wider family system rather than just the individual child (Alvord \& Grados, 2005; Burka, 2007; Evans \& Plumridge, 2007; Ferreyra, 2001; Gauvin-Lepage \& Lefebvre, 2012; Lee et al., 2009; Morison et al., 2003; Mu \& Chang, 2010; Shapiro, 2002), and in some cases included significant others involved with the child, such as teachers (Ferreyra, 2001; Mears \& Stevenson, 2006) and health-care practitioners (Lee et al., 2009; Gauvin-Lepage \& Lefebvre, 2012).

Given the individual nature of disability and chronic illness, it is perhaps not surprising that compared to interventions for typically-developing youth, articles in this review included a highly customised approach to meet individual levels of need (e.g., Ellis et al., 2001; Evans \& Plumridge, 2007; Ferreyra, 2001; Gauvin-Lepage \& Lefebvre, 2012; Leve et al., 2009; Macpherson et al., in press; Morison et al., 2003; Mu \& Chang, 2010; Pelchat, 2010; Shapiro, 2002; Theron, 2006; Woodier, 2011), often informed by a focus group or collaboration with the children, young people and their families (e.g., Ellis et al., 2001; Ferreyra, 2001; Gauvin-Lepage \& Lefebvre, 2012; Macpherson et al., in press; Pelchat, 2010; Storch et al., 2012). By contrast, only two interventions used a universal approach at the level of the classroom and/or school (Firth et al., 2013; Stallard et al., 2005). One program featured an inclusive model of teacher training to change the whole school culture, and a coping program for students with dyslexia, nested within a whole-class coping program aimed at all students in that year (Firth et al., 2013). Whilst they excluded pupils with other types of reading difficulties (from lack of opportunity, learning difficulties, Asperger syndrome, sensory impairment, or emotional difficulties), those pupils (assuming they were present) still received the general whole-class coping skills intervention. Unfortunately the results of this well-intentioned, sustainable intervention were weak, with minimal improvement, lack of difference between dyslexic/non-dyslexic students at the start or end of the study, and observed benefits that could have been the result of the passage of time. 
International Journal of Child, Youth and Family Studies (2014) 5(3): 394-422

Table 1: Summary of contexts, interventions and delivery (where given). (SES=SocioEconomic Status; M=Male; F=Female).

\begin{tabular}{|c|c|c|c|c|c|}
\hline Study & Children \& young people & Age & No. & Delivery & Other info \\
\hline \multirow[t]{2}{*}{$\begin{array}{l}\text { Alvord \& Grados, } \\
\text { 2005; USA }\end{array}$} & $\begin{array}{l}\text { ADHD, anxiety, limited number with "mild" Asperger's, learning } \\
\text { disabilities, fine-motor/gross-motor skills deficits (all) }\end{array}$ & $4-14$ yrs & - & $\begin{array}{l}\text { 24-28 sessions over } 2 \text { semesters; } \\
\text { clinician facilitator }\end{array}$ & $\begin{array}{l}\text { not }<\text { average IQ or } \\
\text { aggression/ antisocial }\end{array}$ \\
\hline & $\begin{array}{l}\text { Details: Facilitated, single-sex, goal-oriented social skills group to learn ne } \\
\text { homework. Outcome: Empirical data collected but not included. }\end{array}$ & N skills; incl & free play, & xation training, active parental invol & ement, reward system and \\
\hline \multirow[t]{2}{*}{$\begin{array}{l}\text { Bloemhoff, 2006; } \\
\text { South Africa }\end{array}$} & $\begin{array}{l}\text { Behavioural and/or emotional problems (e.g., depression, anti-social } \\
\text { behaviour) (all); at-risk, referred under Child Care Act } 1983\end{array}$ & 16 yrs & $47(\mathrm{M})$ & $\begin{array}{l}\text { One-off 4hr session; researcher } \\
\text { facilitator }\end{array}$ & \\
\hline & $\begin{array}{l}\text { Details: Ropes course in environment of 'safe' risk-taking and competition; } \\
\text { Significant increase in protective factors after course compared to before. }\end{array}$ & followed by & ed pr & and reflection to apply learning & eal life. Outcome: \\
\hline \multirow[t]{2}{*}{$\begin{array}{l}\text { Buckner et al., } \\
\text { 2005; USA }\end{array}$} & Asthma (all); Caucasian \& African American; low \& moderate-high SES & $12-14$ yrs & $\begin{array}{l}12(8 \mathrm{~F} \\
4 \mathrm{M})\end{array}$ & 3 day camp; nurses, camp staff & \\
\hline & $\begin{array}{l}\text { Details: Residential camp including outdoor physical/leisure activities, suc } \\
\text { resilience after camp compared to before, improvement still present at } 6 \mathrm{~m}\end{array}$ & as canoeing & country da & ng, combined with asthma educatior & Outcome: Increased \\
\hline \multirow[t]{2}{*}{$\begin{array}{l}\text { Burka, } \\
\text { USA }\end{array}$} & $\begin{array}{l}\text { Learning challenges (e.g., learning disability, ADHD) or medical } \\
\text { problems (e.g., diabetes, cerebral palsy) (all) }\end{array}$ & $8-13$ yrs & 49 & $\begin{array}{l}\text { 3hrs a day, } 5 \text { days a week for } 3 \\
\text { weeks; program staff }\end{array}$ & \\
\hline & $\begin{array}{l}\text { Details: Summer program of challenging but fun activities; included indivi } \\
\text { for reaching goals. Outcome: Not reported. }\end{array}$ & lual work, al & crafts, co & g and problem-solving skills, earnin & non-competitive awards \\
\hline $\begin{array}{l}\text { Ellis et al., 2001; } \\
\text { USA }\end{array}$ & $\begin{array}{l}\text { Learning, emotional, attention hyperactivity disorders (some); at-risk, } \\
\text { referred from judicial/mental health services; low SES }\end{array}$ & $12-18 \mathrm{yrs}$ & 72 & $\begin{array}{l}\text { 2-5 evenings; program staff, } \\
\text { therapeutic recreation specialists }\end{array}$ & Participatory \\
\hline
\end{tabular}


International Journal of Child, Youth and Family Studies (2014) 5(3): 394-422

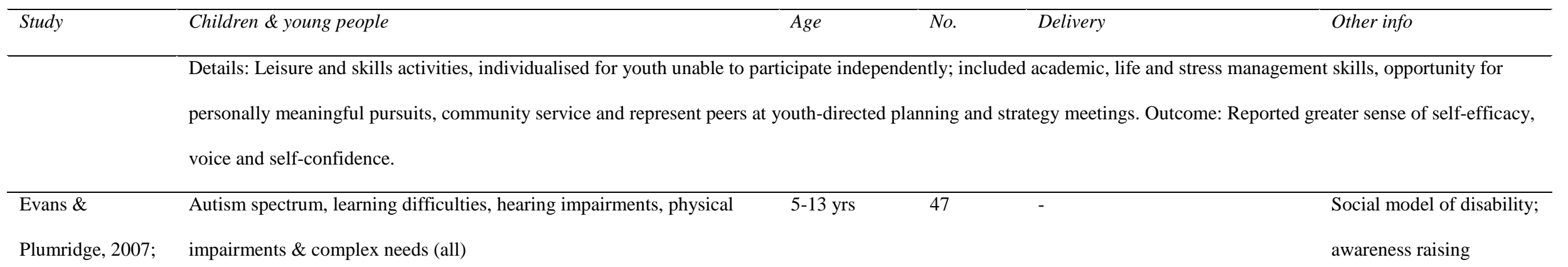

England $\quad$ Details: Wide-ranging inclusive, integrated and specialist play and leisure provision, such as after-school clubs, holiday play-schemes; included specialist information and advice, respite, advocacy and peer support for families. Outcome: Reported increased confidence and self-esteem, reduced isolation.

\begin{tabular}{|c|c|c|c|c|c|}
\hline \multirow[t]{2}{*}{ USA } & $\begin{array}{l}\text { Specific learning difficulties (e.g., dyscalculia, dyslexia, dysgraphia, } \\
\text { dysphasia, ADHD, motor/social perceptual learning disability) and/or } \\
\text { physical disability (cerebral palsy, spina bifida, spinal cord injury, } \\
\text { amputee, speech disabilities) (all); African American, Latina, Asian } \\
\text { American, Native American, Caucasian; from economically } \\
\text { challenged/diverse neighbourhoods }\end{array}$ & $14-21$ yrs & $-\mathrm{F}$ & $\begin{array}{l}\text { 1-3hrs a week during school year } \\
\text { for } 2 \text { yrs; program staff with } \\
\text { disabilities }\end{array}$ & $\begin{array}{l}\text { Addresses basics; } \\
\text { participatory }\end{array}$ \\
\hline & $\begin{array}{l}\text { Details: Facilitated group and one-to-one counselling; focus group develo } \\
\text { awareness/rights and identity formation; provided adult female disabled rc } \\
\text { academic resilience, confidence and social capital, decreased substance us }\end{array}$ & e models anc & $\begin{array}{l}\text { ponsive c } \\
\text { with basi }\end{array}$ & $\begin{array}{l}\text { ulum including life-skills, substance } \\
\text { ing support, food, clothing and shel }\end{array}$ & $\begin{array}{l}\text { use prevention, disability } \\
\text { Outcome: Increased }\end{array}$ \\
\hline \multirow[t]{2}{*}{$\begin{array}{l}\text { Firth et al., 2013; } \\
\text { Australia }\end{array}$} & Dyslexia (some); Anglo-European; 1/3 receiving maintenance allowance & $10-11$ yrs & $\begin{array}{l}23(8 \mathrm{~F}, \\
15 \mathrm{M})\end{array}$ & 10 x 50mins weekly; teachers & \\
\hline & \multicolumn{5}{|c|}{$\begin{array}{l}\text { Details: Dyslexia-specific coping skills program in addition to whole-class CBT program for all students, whole-school changes in practice (e.g., teacher training, studen } \\
\text { screening) and dyslexia-friendly environment (e.g., nonprint-based access to curriculum and means of expression). Outcome: Inconclusive - authors suggest measured }\end{array}$} \\
\hline
\end{tabular}


International Journal of Child, Youth and Family Studies (2014) 5(3): 394-422




International Journal of Child, Youth and Family Studies (2014) 5(3): 394-422

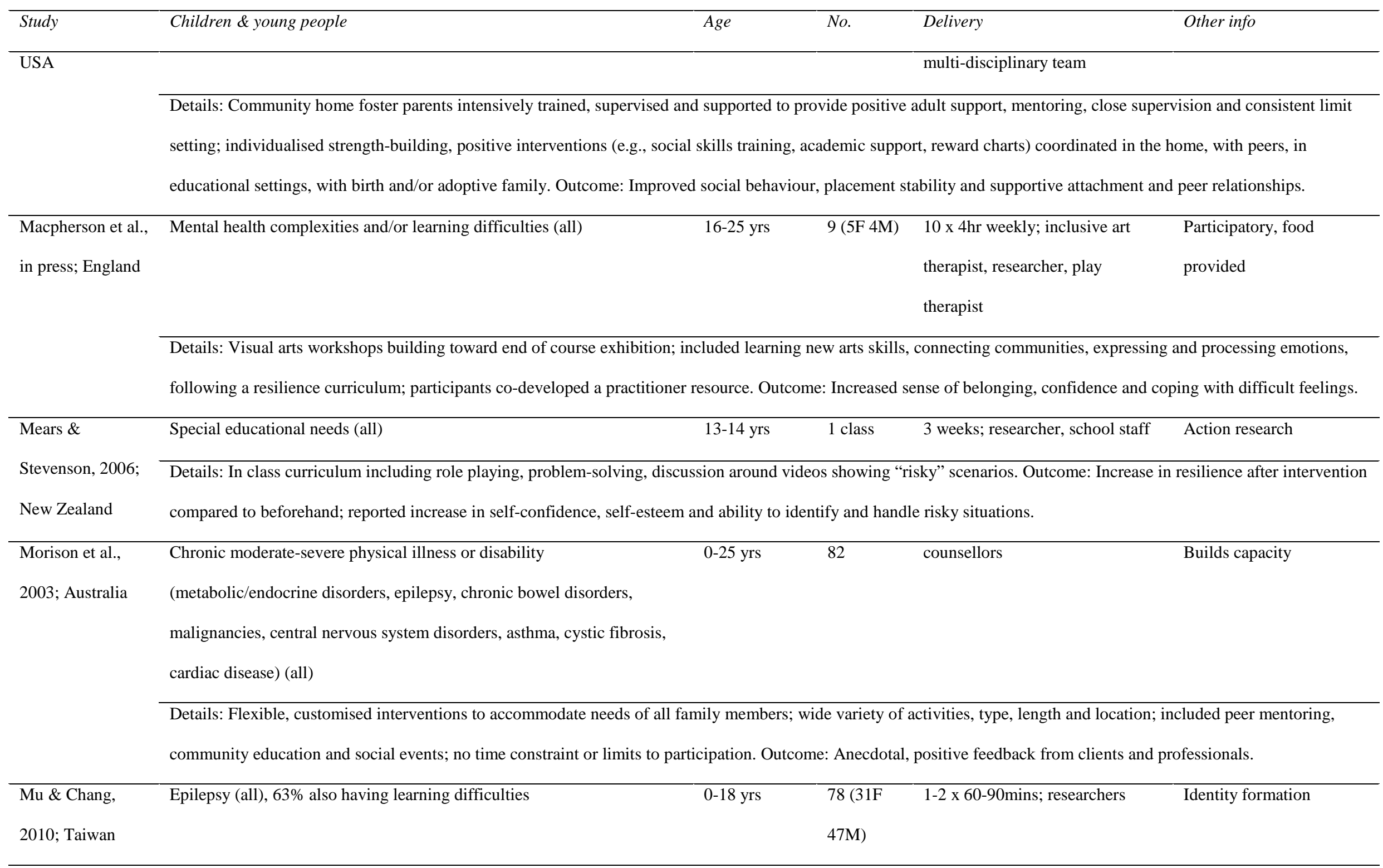


International Journal of Child, Youth and Family Studies (2014) 5(3): 394-422

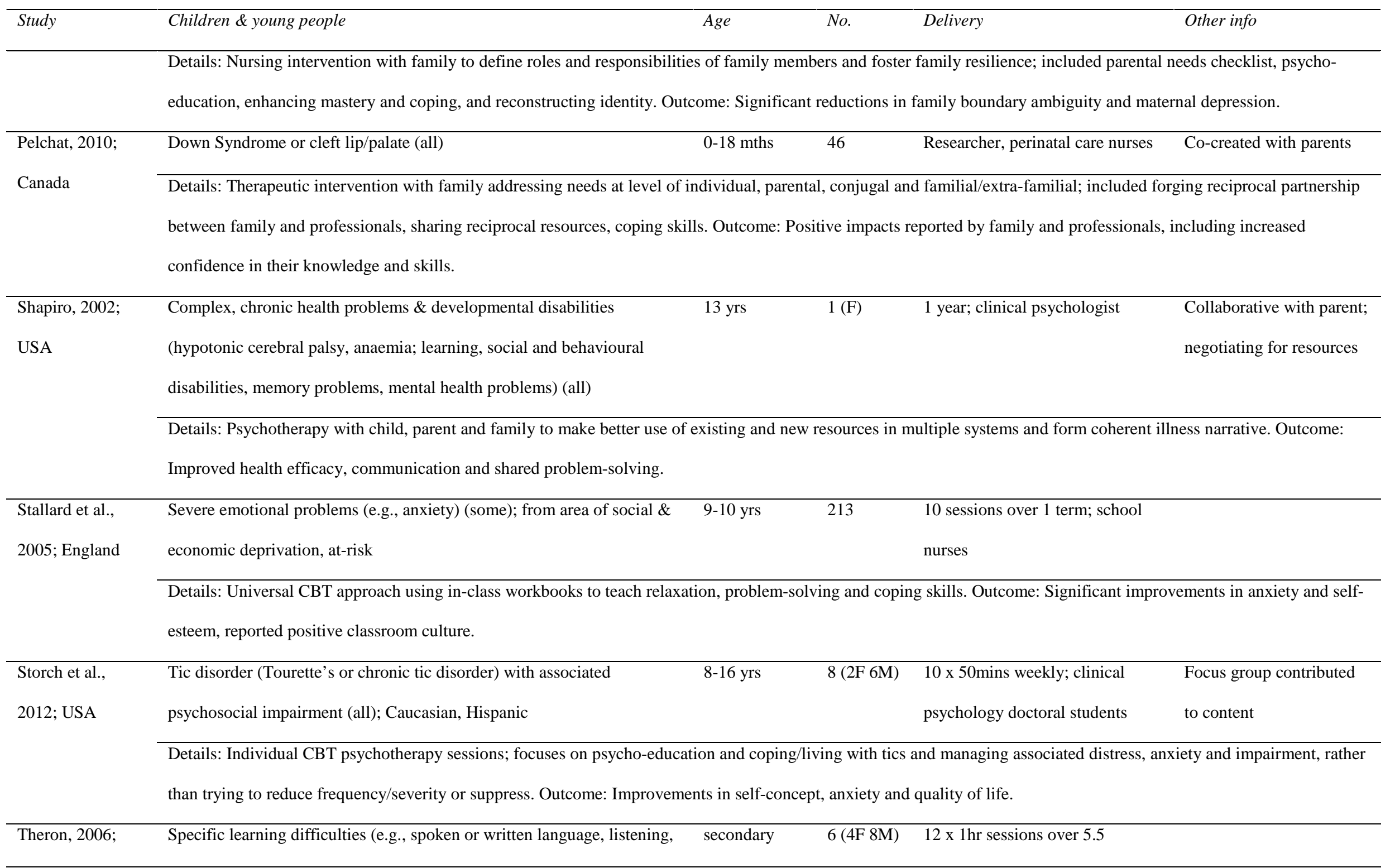


International Journal of Child, Youth and Family Studies (2014) 5(3): 394-422

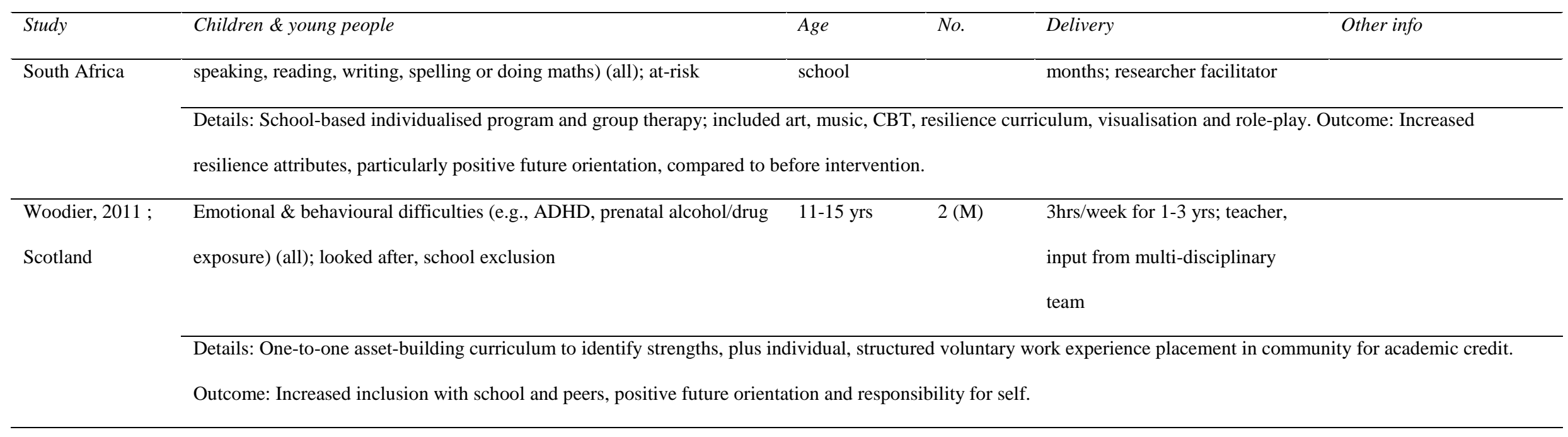


Some of the interventions built capacity, for example the Paediatric and Adolescent Support Service included a parent peer mentoring scheme where parents who had "been there, done that" received training as volunteer mentors for other parents, acting as role models and gaining "recognition for their value as experienced people with much to offer others" (Morison et al., 2003, pp. 127-128). Having parents or young people developing and/or delivering training, for example in the manner of the Amaze charity in Brighton, U.K. (Hart, Virgo, \& Aumann, 2006), and the Experience in Mind community group, also in Brighton, (Taylor, \& Hart, 2011), enables interventions to involve the most excluded parents and young people, potentially makes groups more sustainable, and builds training capacity and the wider social capital of parents and young people.

Noticeably, despite the important resilience-building benefits of encouraging hobbies, talents, and interests (e.g., Gilligan, 1999; Jessup et al., 2010), these dimensions appear to have been left out of most resilience-based interventions for children and young people, as we have found in earlier work (Hart \& Heaver, 2013). Arguably, their inclusion in resilience programs is even more important for disabled children and young people, as they are already being given fewer opportunities and resources than their typically-developing peers. Funded programs usually come with significant resources. Using some of these to develop hobbies and interests could result in an impressive return on investment, laying the foundations for meaningful activities and job opportunities in adulthood.

Other papers in the search that did not include an intervention but were worth mentioning for their strategies and models addressing specific resilience capacities in special education include Jones (2011), Hartley (2010), and Kourkoutas and Xavier (2010).

\section{Exclusion through disability-blindness and an ableist mindset}

Analysis of this data set leads us to suggest that children and young people with complex needs are unjustly under-represented in study samples. Our view prior to undertaking this review, that resilience-focused interventions seemed to exclude the very people who might need them the most, has been confirmed. These marginalised children and young people already have fewer chances and a greater need for intervention, yet some of the most generously funded studies continue to deliberately exclude children and young people with complex needs. Some studies such as repetitions of the Penn Resiliency Program (PRP) often target what are termed "sub-clinical" samples, with a preventative focus on "teaching skills for promoting positive experiences or coping with everyday problems, rather than addressing clinical levels of symptoms that might require advanced clinical training to address” (Kranzler, Parks, \& Gillham, 2011, p. 486). A social-skills group therapy model excluded children and young people with "below average intellectual capability or severe aggression”, rather than providing additional support to sessions, on the basis that these youth would be antisocial, and that "placing antisocial youth together results in interventions that are often ineffective and may even increase the likelihood of delinquency" (Alvord, \& Grados, 2005, p. 242). Somewhat in opposition to the research ethos the authors are advocating, one study took Functional Analysis, an approach designed for students with severe disabilities, behavioural problems, or emotional disorders, and applied it preventatively to children who had no identified disabilities, but who showed "mild behavioural challenges in regular education classrooms” (Stoiber \& Gettinger, 2011, p. 689), described as talking in class when they shouldn't, or not staying in their seat.

For most studies, exclusion was more subtle, reducing the likelihood of their cohort including any children and young people with complex needs by: (a) using written or 
computer-administered program materials that may be inaccessible to students with learning, reading, or communication difficulties (we know from experience that the concepts included in commonly-used resilience scales can be difficult to convey to participants with moderate learning difficulties, and to students in chronic pain who may not be able to concentrate or process much information at one time); (b) taking opportunity samples from low-risk mainstream schools, where disabled pupils who do attend mainstream school may still be absent on the day that the intervention takes place through ill-health, illegal exclusion, or lack of inclusive provision (e.g., Grunstein \& Nutbeam, 2006); (c) using university undergraduate populations where students are less likely to have a moderate to severe learning difficulty (e.g., Stallman, 2011); (d) conducting program activities that are inaccessible or non-adapted, or which take place in a location inaccessible to students with physical disabilities (e.g., Ewert \& Yoshino, 2011); or (e) conducting an intervention in a workplace (e.g., Bennett, Aden, Broome, Mitchell, \& Rigdon, 2010) when young people with disabilities aged 16 to 25 have a rate of unemployment two to four times higher than those without disabilities (Burchardt, 2005).

Standardised Cognitive Behavioural Therapy (CBT) programs may not be accessible for children and young people with learning difficulties. They might struggle with aspects such as identifying thoughts, separating thoughts from feelings, and learning and applying new information and concepts (Mirow, 2008). These children and young people require creative individual adaptation to meet their needs, such as using simple language, including parents/carers, and actually having a less collaborative, more directive, approach (Willner, 2009).

We do not mean to imply that all these studies necessarily set out to exclude children and young people with disabilities and complex needs, but their prevalence in the research evidence base suggests a level of disability blindness and an "ableist mindset” (e.g., Butler, \& Parr, 1999; Chouinard, Hall, \& Wilton, 2010), along with an absence of an "inequalities imagination” (Hall \& Hart, 2004; Hart, Hall, \& Henwood, 2003). Even when researchers are aware of inequality and inclusion issues, they may be guided by different definitions of an "inclusive” program. For example, inclusion may be achieved through additional separate "specialist provision" giving disabled children and young people similar opportunities to their non-disabled peers; additional "integrated activities" that disabled and non-disabled children and young people both participate in together; or supporting disabled children and young people to be safely integrated into mainstream provision by providing equal access to existing play and leisure activities (Evans, \& Plumridge, 2007).

Evans and Plumridge (2007) reported that some services actually "rais[ed] awareness of the needs of disabled children and attempted to change the practice of mainstream providers” (p. 235) through providing deaf awareness and British Sign Language training for mainstream services, and "tackl[ing] disabling barriers within all the spheres of children's lives” (p. 231). However, overall, few interventions addressed consciousness-raising, or the basics, such as giving participants a decent breakfast. These arenas would be included in resilience interventions that took inequalities seriously. For future resilience-based interventions we consider that an "inequalities imagination" (Hart et al., 2003) is needed on the part of the designers and deliverers, to ensure that resilience-based approaches act as political moves against the structural and power inequality manifest in some children and young people's lives, through poverty, marginalisation, unemployment, and constellated disadvantage (Hart et al., 2007; Hart et al., 2003; Prilleltensky \& Prilleltensky, 2005).

Addressing basic inequalities and lack of access to developmentally-appropriate resources has been authoritatively described as the single most important step in improving mental health 
outcomes (Friedli, 2009; Layard, 2005), yet is rarely explicitly considered and worked with beyond citing contextual issues relating to the child's social ecology, even when interventions target disadvantaged populations. This may partly be due to difficulty in defining what constitutes disadvantage, and how it is located and measured (Hart et al., 2007; Mayer, 2003; Prilleltensky \& Prilleltensky, 2005).

There are also other, more subtle political issues of disability rights to be considered. Children and young people with disabilities have been regarded as a small group that is difficult to visualize. But this viewpoint does not reflect reality. In Sweden about 14 to $18 \%$ of young people in secondary and upper-secondary school report that they have one or more disabilities (Brunnberg, Lindén Boström, \& Persson, 2009), with 3\% reporting multiple disabilities (Brunnberg \& Olsson, 2013). The political goal for disabled children and young people in many countries has been "equality", but this has in many contexts centred on equality in attending, for example, the same school as their non-disabled peers. Equality has not been a concept of quality, for example, in education or communication. Children and young people with disabilities have the equal right to be heard and listened to, and to be treated in the best way (UNICEF, 2013a). This should apply to their meaningful participation in research studies, both as participants and, ideally, as collaborators in the research process and intervention design. More than 20 years ago, Oliver (1992) made the point that disability research "has had little influence on policy and made no contribution to improving the lives of disabled people” (p. 101), and could even be described as "alienating” (p. 101) rather than emancipatory. It feels as though little has changed.

In terms of balancing the cost efficiency of time and resources against helping those most in need, more debate needs to occur amongst researchers regarding where it is realistic and ethical to draw the line. Sometimes it is clear how the balance has been reached; for example, Storch et al.'s (2012) CBT program for young people with tic disorders was contextual and participatory - focusing on coping skills specific to living with tics, and conducting focus groups with the youths themselves to inform the content of the course. It was delivered via one-to-one psychotherapy sessions, making it resource-intensive. Costs were reduced by having doctoral students deliver the sessions, rather than more qualified therapists, and by keeping the program to ten weekly sessions of 50 minutes each. A consequence of using less experienced practitioners conducting a short program was that young people with more complex needs (e.g., having a "comorbid" diagnosis), who therefore might require a greater level of support, were excluded from participating. Providing intensive, contextualised, and customised interventions via experienced practitioners is expensive; the higher the cost, the fewer children and young people having the opportunity to benefit; the greater the level of customisation, the less generalisable it may be, with a reduced economy of scale. Funders may be more willing to award money to a marketable prevention program that states it will help 50 children now and could be rolled out to 500 in the future, than to an intervention that costs the same and will help five children with complex needs in the here and now.

The political economy and market orientation of research, or "academic capitalism" (Barry, 2011), promotes the use of "tame" populations and means that money is usually spent on typically-developing children and young people with average levels of need. Research often focuses on those who will sit quietly and complete the measures that the researchers are interested in, with minimal supervision and in the fastest time. The children and young people who are most in need of resilience-based interventions are left out because they may need support to participate in the study; those support needs will need to be assessed; suitably qualified and experienced researchers/practitioners will need to be part of the team, or training 
will need to be provided in order to sensitively and appropriately support participants; scales/measures will need to be adapted, not only in terms of presentation in a suitably accessible format (e.g., short sentences, easy read, or pictorial), but also in terms of concepts that are meaningful and relevant to the participants (e.g., not asking about activities that participants are unable to do), and not making assumptions (e.g., that having lots of friendships is necessarily beneficial or desirable to someone with autism); extra time will need to be built into the research project to allow for supported participation, which may also need co-operation and co-ordination of parent, carer or trusted adult attendance at sessions, or arrangement of appropriate transport and travel expenses.

Children and young people with complex needs are less likely to form a convenient opportunity sample, in contrast to pupils in a large mainstream school. The authors know that it is immensely difficult to keep participants with learning difficulties involved in research, but it is politically, morally, and ethically very important. Other researchers could learn from, for example, the Swedish study "Life and Health” (Brunnberg \& Olsson, 2013) in which students with different types of disabilities could read and answer the survey in sign language, talked language, spelling with big letters, as well as in a traditional format as text. While the survey was still not presented in easy-to-read text, it did however have a high response rate and was more inclusive than most.

In studies where researchers do not specify the participant demographics, it is easy to work out that they have not included children and young people with disabilities, based on the description of the work, the questionnaires they used to evaluate the program, the level of staffing, and the lack of tailoring for individuals. Some programs are implicitly ableist, for example developing an exercise or physical activity-based resilience-building intervention, which has not, or cannot, be adapted for different needs. We are advocating a more transparent and reflective approach to the inclusion of disabled children and young people, with the hope that some balance can be achieved. One way to address exclusion might be to acknowledge the tensions between factors - including finances, time constraints, and funding body agendas - from an informed viewpoint, admitting that there are excluded populations and stating reasons for decisions about participants. This in itself might encourage more attention to be paid to what should be done differently to make research more inclusive.

\section{Limitations of the methodology}

This review used the WHO (2012) definition of disability, and the researchers have translated their interpretation of the definition into the search terms and search strategies that were applied. The definition, and its interpretation, will therefore both influence the results of the literature search (e.g., Grönvik, 2009). Iterative evolution of the inclusion criteria introduces a researcher bias to the choice of which studies to include, albeit informed by years of research and practice in this area, but this should be acknowledged reflexively. Such subjective influences make a literature search less replicable and more contextualised. However, given the area of interest, this may be appropriate, and we have tried to make explicit all decisional processes in our strategy.

The articles that were included varied in the degree to which authors had engaged with the resilience evidence base and definitional debates. Therefore the programs included are diverse in their theoretical underpinnings and adherence to resilience principles, and it is unlikely that there was a great deal of overlap in perspectives. However this may reflect broader disagreements over the definition of the terms resilience and disability. Where possible, the authors have tried to highlight studies that take a more socio- 
ecological/inequalities view of resilience (e.g., Hart et al., 2007; Masten, 2011; Rutter, 2006; Ungar, 2012), rather than those focusing on individual traits or characteristics in isolation from contextual issues, and those with a more participatory approach, incorporating the input of the young people with disabilities themselves into the research process.

Additional difficulty in finding comparable studies lies partly in the specific and distinct effects, restrictions, and life-courses of different types of chronic illness and disability (e.g., as per Shapiro (2002), steady, fluctuating, or progressive; impacting predominantly physical, cognitive, or sensory functioning; invoking sympathy or stigma; visible or hidden), which may result in different types of intervention or therapeutic approaches being selected for their benefits and potential fit with the individual. Categories were complex and diverse, and the only "population" where there was any overlap in terms of labels was "behavioural and emotional problems", which is itself a broad umbrella for a range of conditions and severities. Imagining the interplay of the unique effects that a young person's disability has on them, the context of their individual environment, their family and the available resources, leads to an appreciation of the enormous amount of individual difference within a group of children or young people participating in one specific study, let alone between studies. Trying to compare groups from different studies, with the massive variation in resilience-building approaches and activities taken, makes a review of comparable studies with comparable populations and programs almost impossible. It also highlights the even greater need for contextualised understanding of and response to the individual child's situation, rather than standardised, manualised interventions aimed at large groups of typically-developing children and young people in mainstream settings.

\section{Conclusion}

Of the papers identified, only 23 met (at least in part) the inclusion criteria, including a robust resilience concept and basis to the intervention, and a way of measuring changes in the children and young people's resilience. The 23 studies covered a variety of program content, setting, delivery, and children and young people. Due to the lack of evaluated, theoreticallysound programs designed for the needs of children and young people with disabilities, the inclusion criteria were applied more flexibly if the intervention demonstrated solid links to resilience but was not evaluated, or if the intervention lacked a specific definition of resilience but was clearly linked to resilience capacities (e.g., self-esteem). Overall, it was difficult to summarise such sparse and disparate studies in a meaningful way, particularly when small sample sizes and analyses of varying type and quality made it challenging to draw conclusive or comparative results. The authors would like to encourage better research "practice", that will lead to the conducting of rich, informative, and detailed research that is inclusive, participatory, and sustainable in its approach, and suitable to inform a realist review. Whilst this is a very complex goal to realise, our review has provided some evidence for the notion that resilience-based programs hold promise, despite design flaws, small samples, poor definitions, and inconsistent measurement.

The academic publishing landscape has been dramatically changed by recent research council open access policies that hold grant recipients accountable to wider stakeholders and the general public. This may yet provide opportunities for positive developments in relation to the inclusion of disabled children and young people in research. Some journals suggest major demographic characteristics of study samples should be included in the methodology section of new submissions, to "provide a more complete understanding of the sample and of the generalisability of the findings" (American Psychological Association, 2013). The authors suggest that such disclosure should become mainstream within the social sciences: A 
demographics statement that describes which disadvantaged or marginalised groups are included in the sample, including people who identify as having disabilities, should be required as part of project outputs. If no participants are described as experiencing these types of inequality, then a rationale should be provided by the researchers that explains why a nonrepresentative sample has been chosen. In addition to making this information explicit and publicly available, this would increase awareness and shift focus onto inequalities issues. Goodhart's Law identifies that the measurement of a system usually disturbs it (McIntyre, 2000), and the use of non-representative opportunity samples in large-scale, publicly-funded studies is a system most in need of some disturbance.

The overall flavour of the resilience and disability research evidence base is of measuring how things are, and identifying fairly fixed characteristics of individuals which are associated with better outcomes. Practitioners wishing to know what they can do right now to help disabled children and young people make resilient moves within the context of their own lives, can experience the literature as frustrating, difficult to digest, and hard to learn from. There is often a huge gap between what research reports, and what people want to know and learn about when working in the messy, complexity of situated practice. The research world must do more to answer the questions of parents and practitioners who support children and young people with disabilities and complex needs. Researchers also need to think of ways to capture the views, needs and experiences of children and young people with disabilities to ensure the relevance of their interventions. Children and young people with highly complex needs were of specific interest to the parents and practitioners we consulted, and we can infer from the papers in our review that, perhaps unsurprisingly, these children and young people responded to high intensity, individually-customised interventions.

Given the high level of illegal school exclusions experienced by disabled children and young people in England and Wales (Contact a Family, 2013), with devastating effects on their basic education, coupled with the well-documented disadvantages they face throughout their lives, more effort should be made to focus resilience-based interventions on supporting children, young people, their families and schools, to undo this damaging practice. Young people beyond the age of 18 were rarely included in studies, therefore research and practice developments could target older populations who may be as, or even more, socially-excluded than their younger peers. Finally, it is a great irony that third-sector organisations, which are far less resourced than universities, are doing the most research with disabled children and young people (e.g., Burchardt, 2005; Contact a Family, 2013). Academics based in universities could, as a start, team up with these organisations to lend support in taking this much-needed dimension of resilience research and practice development forward. 


\section{References}

Alvord, M. K., \& Grados, J. J. (2005). Enhancing resilience in children: A proactive approach. Professional Psychology: Research and Practice, 36(3), 238-245. doi: $\underline{10.1037 / 0735-7028.36 .3 .238}$

American Psychological Association. (2013). Developmental psychology. Retrieved from http://www.apa.org/pubs/journals/dev/index.aspx?tab=4\#submit

Barry, J. (2011). Knowledge as power, knowledge as capital: A political economy critique of modern 'academic capitalism'. Irish Review, 43, 14-25.

Bennett, J. B., Aden, C. A., Broome, K., Mitchell, K., \& Rigdon, W. D. (2010). Team resilience for young restaurant workers: Research-to-practice adaptation and assessment. Journal of Occupational Health Psychology, 15(3), 223-236. doi: $10.1037 / \mathrm{a} 0019379$

Bloemhoff, H. J. (2006). Impact of facilitation on the effectiveness of an adventure-based recreation programme for the development of resiliency in at-risk adolescent boys confined to a rehabilitation centre. African Journal for Physical, Health Education, Recreation and Dance, 12(2), 138-151.

Brunnberg, E., Lindén Boström, M., \& Berglund, M. (2007). Self-rated health, school adjustment and substance use in hard-of-hearing adolescents with multiple disabilities. Journal of Deaf Studies and Deaf Education, 13(3), 324-335. doi: $\underline{10.1093 / \text { deafed/enm062 }}$

Brunnberg, E., Lindén Boström, M., \& Berglund, M. (2012). Sexual force at sexual debut. Swedish adolescents with disabilities at higher risk than adolescents without disabilities. Child Abuse \& Neglect, 36(4), 285-295. doi:10.1016/j.chiabu.2012.01.002

Brunnberg, E., Lindén Boström, M., \& Persson, C. (2009). Att höra eller nästan inte höra. Liv \& hälsa ung 2005 och 2007 i Örebro län. Örebro: Örebro läns landsting.

Brunnberg, E., \& Olsson, S. (2013). Liv \& Hälsa Ung 2011. Eskilstuna: Mälardalen University.

Buckner, E. B., Hawkins, A. M., Stover, L., Brakefield, J., Simmons, S., Foster, C., et al. (2005). Knowledge, resilience, and effectiveness of education in a young teen asthma camp. Pediatric Nursing, 31(3), 201-207.

Burchardt, T. (2005). The education and employment of disabled young people: Frustrated ambition. Bristol: Joseph Rowntree Foundation. Retrieved from http://www.jrf.org.uk/sites/files/jrf/1861348363.pdf

Burka, A. A. (2007). Resiliency building program for children. The Ochsner Journal, 7(4), 177-180.

Butler, R., \& Parr, H. (Eds.). (1999). Mind and body spaces: Geographies of illness, impairment and disability. London: Routledge. 
Chouinard, V., Hall, E., \& Wilton, R. (Eds.). (2010). Towards enabling geographies: "disabled" bodies and minds in society and space. Farnham, Surrey: Ashgate Publishing Limited.

Contact a Family. (2013). Falling through the net: Illegal exclusions. The experience of families with disabled children in England and Wales (2013). London: Contact a Family. Retrieved from http://www.cafamily.org.uk/media/639982/falling_through_the_net__illegal_exclusions_report_2013_web.pdf

Cosden, M. (2001). Risk and resilience for substance abuse among adolescents and adults with LD. Journal of Learning Disabilities, 34(4), 352-358. doi: $10.1177 / 002221940103400410$

Doob, A., \& Cesaroni, C. (2004). Responding to youth crime in Canada. Toronto: University of Toronto Press.

Ellis, J. M., Braff, E., \& Hutchinson, S. L. (2001). Youth recreation and resiliency: Putting theory into practice in Fairfax County. Therapeutic Recreation Journal, 35(4), 307-317.

Evans, R., \& Plumridge, G. (2007). Inclusion, social networks and resilience: Strategies, practices and outcomes for disabled children and their families. Social Policy and Society, 6(2), 231-241. doi:10.1017/S1474746406003496

Ewert, A., \& Yoshino, A. (2011). The influence of short-term adventure-based experiences on levels of resilience. Journal of Adventure Education \& Outdoor Learning, 11(1), 35-50. doi: $\underline{10.1080 / 14729679.2010 .532986}$

Ferreyra, N. (2001). Living out loud: Building resiliency in adolescent girls with disabilities. Disability World, 7. Retrieved from http://www.disabilityworld.org/03$\underline{\text { 04_01/women/lol.shtml }}$

Firth, N., Frydenberg, E., Steeg, C., \& Bond, L. (2013). Coping successfully with dyslexia: An initial study of an inclusive school-based resilience programme. Dyslexia, 19(2), 113-130. doi: $10.1002 /$ dys.1453

Forsyth, R., \& Jarvis, S. (2002). Participation in childhood. Child: Care, Health and Development, 28(4), 277-279. doi:10.1046/j.1365-2214.2002.00272.x

Friedli, L. (2009). Mental health, resilience and inequalities. Copenhagen: WHO Europe.

Gauvin-Lepage, J., \& Lefebvre, H. (2012). Resilience in families of adolescents with severe traumatic brain injuries: Development of a support intervention. Brain Injury, 26(4-5), 315-316.

Gilligan, R. (1999). Enhancing the resilience of children and young people in public care by mentoring their talents and interests. Child and Family Social Work, 4(3), 187-196. doi: $10.1046 / \mathrm{j} .1365-2206.1999 .00121 . \mathrm{x}$ 
Goodley, D. (2005). Empowerment, self-advocacy and resilience. Journal of Intellectual Disabilities, 9(4), 333-343. doi:10.1177/1744629505059267

Groce, N. E. (2004). Adolescents and youth with disabilities: Issues and challenges. Asia Pacific Disability Rehabilitation Journal, 15(2), 13-32.

Grönvik, L. (2009). Defining disability: Effects of disability concepts on research outcomes. International Journal of Social Research Methodology, 12(1), 1-18. doi:10.1080/13645570701621977

Grunstein, R., \& Nutbeam, D. (2006). The impact of participation in the Rock Eisteddfod challenge on adolescent resiliency and health behaviours. Health Education, 107(3), 261-275. doi:10.1108/09654280710742564

Gwernan-Jones, R. (2008). Identity and disability: A review of the current state and developing trends. Retrieved from http://www.beyondcurrenthorizons.org.uk/identityand-disability-a-review-of-the-current-state-and-developing-trends/

Hall, V., \& Hart, A. (2004). The use of imagination in professional education to enable learning about disadvantaged clients. Learning in Health and Social Care, 3(4), 190202. doi:10.1111/j.1473-6861.2004.00074.X

Hart, A., \& Heaver, B. (2013). Evaluating resilience-based programs for schools using a systematic consultative review. Journal of Child and Youth Development, 1(1), 27-53. Retrieved from https://journals.ub.uni-osnabrueck.de/index.php/jcyd/article/view/16

Hart, A., Blincow, D., \& Thomas, H. (2007). Resilient therapy: Working with children and families. London: Routledge.

Hart, A., Hall, V., \& Henwood, F. (2003). Helping health and social care professionals develop an 'inequalities imagination': A model for use in education and practice. Journal of Advanced Nursing, 41(5), 480-489. doi:10.1046/j.1365-2648.2003.02555.X

Hart, A., Virgo, S., \& Aumann, K. (2006). Insiders' guide to bringing up children with special needs: Evaluation of the Amaze parent support course. Brighton, UK: Amaze.

Hartley, M. T. (2010). Increasing resilience: Strategies for reducing dropout rates for college students with psychiatric disabilities. American Journal of Psychiatric Rehabilitation, 13(4), 295-315. doi:10.1080/15487768.2010.523372

Hosseinpoor, A. R., Stewart Williams, J. A., Gautam, J., Posarac, A., Officer, A., Verdes, E., et al. (2013). Socioeconomic inequality in disability among adults: A multicountry study using the world health survey. American Journal of Public Health, 103(7), 12781286. doi:10.2105/AJPH.2012.301115

Hughes, N., Williams, H., Chitsabesan, P., Davies, R., \& Mounce, L. (2012). Nobody made the connection: The prevalence of neurodisability in young people who offend. London: The Office of the Children's Commissioner. Retrieved from http://www.childrenscommissioner.gov.uk/content/publications/content_633 
Hutcheon, E., \& Wolbring, G. (2013). Deconstructing the resilience concept using an ableism lens: Implications for people with diverse abilities. Dilemata, International Journal of Applied Ethics, 5(11), 235-252.

Irie, Y., \& Tsumura, C. (2011). Development of a family intervention model to facilitate resilience in families of children with intellectual disabilities. Journal of Japan Academy of Nursing Science, 31(4), 34-45.

Janssen, I., \& Leblanc, A. G. (2010). Systematic review of the health benefits of physical activity and fitness in school-aged children and youth. International Journal of Behavioral Nutrition and Physical Activity, 7, 40. doi:10.1186/1479-5868-7-40

Jessup, G. M., Cornell, E., \& Bundy, A. C. (2010). The treasure in leisure activities: Fostering resilience in young people who are blind. Journal of Visual Impairment \& Blindness, 104(7), 419-430.

Jones, E., Gutman, L., \& Platt, L. (2013). Family stressors and children's outcomes. London: Childhood Wellbeing Research Centre.

Jones, V. (2011). Resiliency instructional tactics: African American students with learning disabilities. Intervention in School and Clinic, 46(4), 235-239. doi:10.1177/1053451210389032

Kourkoutas, E. E., \& Xavier, M. R. (2010). Counseling children at risk in a resilient contextual perspective: A paradigmatic shift of school psychologists' role in inclusive education. Procedia Social \& Behavioral Sciences, 5, 1210-1219. http://dx.doi.org/10.1016/j.sbspro.2010.07.263

Kranzler, A., Parks, A., \& Gillham, J. (2011). Illustrating positive psychology concepts through service learning: Penn teaches resilience. The Journal of Positive Psychology, 6(6), 482-486. doi:10.1080/17439760.2011.634829

Layard, R. (2005). Happiness: Lessons from a new science. London: Allen Lane.

Lee, M. Y., Greene, G. J., Hsu, K. S., Solovey, A., Grove, D., Fraser, J. S., et al. (2009). Utilizing family strengths and resilience: Integrative family and systems treatment with children and adolescents with severe emotional and behavioral problems. Family Process, 48(3), 395-416. doi:10.1111/j.1545-5300.2009.01291.x

Leve, L. D., Fisher, P. A., \& Chamberlain, P. (2009). Multidimensional treatment foster care as a preventive intervention to promote resiliency among youth in the child welfare system. Journal of Personality, 77(6), 1869-1902. doi:10.1111/j.14676494.2009.00603.x

Macpherson, H. M., Hart, A., \& Heaver, B. (in press). Building resilience through group visual arts activities: Findings from a scoping study with young people who experience mental health complexities and/or learning difficulties. Journal of Social Work. http://dx.doi.org/10.1177/1468017315581772 
Mâsse, L. C., Miller, A. R., Shen, J., Schiariti, V., \& Roxborough, L. (2013). Patterns of participation across a range of activities among Canadian children with neurodevelopmental disorders and disabilities. Developmental Medicine \& Child Neurology, 55(8), 729-736. doi:10.1111/dmcn.12186

Masten, A. S. (2011). Resilience in children threatened by extreme adversity: Frameworks for research, practice, and translational synergy. Development and Psychopathology, 23(2), 493-506. doi:10.1017/S0954579411000198

Mayer, S. E. (2003). What is a “disadvantaged group"? Minneapolis: Effective Communities Project.

McIntyre, M. (2000). Audit, education, and Goodhart's Law: Or, taking rigidity seriously. Retrieved from http://www.atm.damtp.cam.ac.uk/mcintyre/papers/LHCE/goodhart.html

Mears, A., \& Stevenson, R. (2006). Building resiliency in students with special education needs: A journey of discovery. Kairaranga, 7, 53-55.

Mental Health Foundation of Australia. (2005). Embrace the future: Resilient schools program. Retrieved from

http://www.embracethefuture.org.au/resiliency/index.htm?http://www.embracethefuture .org.au/resiliency/resiliency_model.htm

Mirow, R. (2008). 'Going cognitive': CBT for people with learning disabilities. Learning Disability Practice, 11(8), 34-38. http://dx.doi.org/10.7748//dp2008.10.11.8.34.c6791

Morison, J. E., Bromfield, L. M., \& Cameron, H. J. (2003). A therapeutic model for supporting families of children with a chronic illness or disability. Child and Adolescent Mental Health, 8(3), 125-130. doi:10.1111/1475-3588.00058

Mu, P., \& Chang, K. (2010). The effectiveness of a programme of enhancing resiliency by reducing family boundary ambiguity among children with epilepsy. Journal of Clinical Nursing, 19(9-10), 1443-1453. doi:10.1111/j.1365-2702.2009.03075.x

Odgers, C. L., Burnette, M. L., Chauhan, P., Moretti, M. M., \& Reppucci, N. D. (2005). Misdiagnosing the problem: Mental health profiles of incarcerated juveniles. The Canadian Child and Adolescent Psychiatry Review, 14(1), 26-29.

Oliver, M. (1992). Changing the social relations of research production? Disability, Handicap \& Society, 7(2), 101-114. doi:10.1080/02674649266780141

Pawson, R., Greenhalgh, T., Harvey, G., \& Walshe, K. (2005). Realist review: A new method of systematic review designed for complex policy interventions. Journal of Health Services Research \& Policy, 10(S1), 21-34. doi:10.1258/1355819054308530

Pelchat, D. (2010). PRIFAM: A shared experience leading to the transformation of everyone involved. Journal of Child Health Care, 14(3), 211-224. http://dx.doi.org/10.1177/1367493510364166 
Pittet I., Berchtold, A., Akré C., Michaud P. A., \& Suris J. C. (2010) Are adolescents with chronic conditions particularly at risk for bullying? Archives of Disease in Childhood, 95(9), 711-716. doi:10.1136/adc.2008.146571

Prilleltensky, I., \& Prilleltensky, O. (2005). Beyond resilience: Blending wellness and liberation in the helping professions. In M. Ungar (Ed.), Handbook for working with children and youth pathways to resilience across cultures and contexts (pp. 89-103). Thousand Oaks, CA: Sage. http://dx.doi.org/10.4135/9781412976312.n6

Runswick-Cole, K., \& Goodley, D. (2013). Resilience: A disability studies and community psychology approach. Social and Personality Psychology Compass, 7(2), 67-78. doi:10.1111/spc3.12012

Rutter, M. (2006). Implications of resilience concepts for scientific understanding. Annals of the New York Academy of Sciences, 1094, 1-12. doi:10.1196/annals.1376.002

Salvador-Carulla L., \& Gasca, V. I. (2010). Defining disability, functioning, autonomy and dependency in person-centered medicine and integrated care. International Journal of Integrated Care, 10(S25). Retrieved from http://www.ijic.org/index.php/ijic/article/view/495/988

Schalock, R. L., \& Luckasson, R. (2013). What's at stake in the lives of people with intellectual disability? Part I: The power of naming, defining, diagnosing, classifying, and planning supports. Intellectual and Developmental Disabilities, 51(2), 86-93. http://dx.doi.org/10.1352/1934-9556-51.2.094

Shapiro, E. R. (2002). Chronic illness as a family process: A social-developmental approach to promoting resilience. Journal of Clinical Psychology, 58(11), 1375-1384. http://dx.doi.org/10.1002/jclp.10085

Stallard, P., Simpson, N., Anderson, S., Carter, T., Osborn, C., \& Bush, S. (2005). An evaluation of the FRIENDS programme: A cognitive behaviour therapy intervention to promote emotional resilience. Archives of Disease in Childhood, 90(10), 1016-1019. doi:10.1136/adc.2004.068163

Stallman, H. M. (2011). Embedding resilience within the tertiary curriculum: A feasibility study. Higher Education Research \& Development, 30(2), 121-133. doi: $\underline{10.1080 / 07294360.2010 .509763}$

Stoiber, K. C., \& Gettinger, M. (2011). Functional assessment and positive support strategies for promoting resilience: effects on teachers and high-risk children. Psychology in the Schools, 48(7), 686-706. http://dx.doi.org/10.1002/pits.20587

Storch, E. A., Morgan, J. E., Caporino, N. E., Brauer, L., Lewin, A. B., Piacentini, J., \& Murphy, T. K. (2012). Psychosocial treatment improved resilience and reduce impairment in youth with tics: An intervention case series of eight youth. Journal of Cognitive Psychotherapy, 26(1), 57-70. doi:10.1891/0889-8391.26.1.57

Talbot, J. (2010). Seen and heard: Supporting vulnerable children in the youth justice system. Retrieved from http://www.prisonreformtrust.org.uk/Publications/vw/1/ItemID/67 
Taylor, S., \& Hart, A. (2011). Experience in mind: Mental health and the resilient therapy toolkit (A guide for parents about mental health written by young people). Bath: MBE. Retrieved from http://www.boingboing.org.uk

Theron, L. (2006). Critique of an intervention programme to promote resilience among learners with specific learning difficulties. South African Journal of Education, 26(2), 199-214.

Ungar, M. (Ed.). (2012). The social ecology of resilience: A handbook of theory and practice. New York: Springer.

United Nations Children's Emergency Fund (UNICEF). (2013a). Convention on the rights of the child. Retrieved from http://www.unicef.org/crc/

United Nations Children's Emergency Fund (UNICEF). (2013b). The state of the world's children 2013: Children with disabilities. New York: United Nations.

van Campen, C., \& van Santvoort, M. (2013). Explaining low subjective well-being of persons with disabilities in Europe: The impact of disability, personal resources, participation and socio-economic status. Social Indicators Research, 111(3), 839-854. doi: $\underline{10.1007 / s 11205-012-0036-6}$

World Health Organization (WHO). (2007). International classification of functioning, disability and health: Children \& youth version. Geneva: World Health Organization.

World Health Organization (WHO). (2012). Disabilities. Retrieved from http://www.who.int/topics/disabilities/en/

Willner, P. (2009). Psychotherapeutic interventions in learning disability: Focus on cognitive behavioural therapy and mental health. Psychiatry, 8(10), 416-419. doi: 10.1016/j.mppsy.2009.06.018

Woodier, D. (2011). Building resilience in looked after young people: A moral values approach. British Journal of Guidance \& Counselling, 39(3), 259-282. doi: $\underline{10.1080 / 03069885.2011 .562638}$ 